\title{
Parvovirus infection mimicking systemic lupus erythematosus
}

\author{
Mohan Cooray MD, Joshua J. Manolakos MD, Douglas S. Wright MD, Shariq Haider MD, Ameen Patel MD
}

Competing interests: None declared.

This article has been peer reviewed

Correspondence to: Mohan Cooray, mohan.cooray@medportal.ca

CMAJ 2013. DOI:10.1503 /cmaj.121565

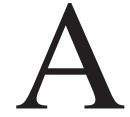
53-year-old woman presented to the emergency department with an itchy, red, reticular rash on her arms and legs. She had a 2-day history of sudden pain and swelling in her wrists, knees and ankles, with associated numbness and tingling of the fingers of both hands. The patient had been in contact with her grandchildren, who did not live with her, who had been having fevers, cold-like symptoms and a "slapped-cheek" facial rash 12 weeks before her presentation. The patient had no family history of any autoimmune or connective tissue disorders.

On examination, the patient was afebrile. There was joint tenderness in her wrists, knees and ankles, a reticular rash on the flexor surface of both arms and a petechial rash on the tibial surface of both legs. There was no discolouration to suggest Raynaud phenomenon and no palpable joint effusion.

Laboratory investigations showed a leukocyte count of $2.9 \times 10^{9}$ (normal 1.0-11.0 $\times$ $10^{9}$ ) cells $/ \mathrm{L}$, with an absolute neutrophil count of $1.5 \times 10^{9}\left(\right.$ normal $\left.2.0-7.5 \times 10^{\circ}\right)$ cells $/ \mathrm{L}$ and a lymphocyte count of $1.0 \times 10^{9}$ (normal $\left.1.5-4.0 \times 10^{9}\right)$ cells/L. The patient's hemoglobin concentration was 133 (normal 115-165) g/L, her platelet count was 129 (normal 150-400) $\times 10^{9}$ cells/L, her erythrocyte sedimentation rate was 19 (normal $<20$ ) $\mathrm{mm} / \mathrm{h}$, and her C-reactive protein level was 5.1 (normal < 10) $\mathrm{mg} / \mathrm{L}$. Results of tests for electrolytes, extended electrolytes (e.g., calcium, magnesium), liver enzymes, renal function, creatinine kinase and B-human chorionic gonadotropin were all normal, as were the results of an electrocardio- gram and urinalysis. The results of an antinuclear antibody screen were positive and the titre for anti-double-stranded DNA was elevated (40 [nor$\mathrm{mal}<4] \mathrm{IU} / \mathrm{mL}$ ), with an anticardiolipin titre of 23 (normal < 15) GPL units $(1 \mathrm{GPL}$ unit $=1 \mu \mathrm{g}$ immunoglobulin G). Serologic tests for rheumatoid factor, antibodies to Sjögren syndrome antigen B (anti-SSB) and antibodies to Smith antigen (anti$\mathrm{Sm}$ ) were nonreactive. There was evidence of hypocomplementemia (complement component 3 [C3] concentration 0.64 [normal 0.73-1.73] g/L; complement component 4 [C4] concentration $<0.02$ [normal 0.13-0.52] g/L). Serologic testing showed elevated immunoglobulin M (3.19 [normal 0.41-2.07] g/L), with normal levels of other immunoglobulins. Radiographic images of the ankles, knees, wrists and chest appeared normal.

This clinical presentation with the antecedent history of viral exposure suggested parvovirus infection. Four days after the onset of the patient's symptoms, the results of serologic and polymerase chain reaction (PCR) testing for parvovirus B19 confirmed acute infection.

The patient's symptoms resolved within 2 3 weeks. Two years after the initial presentation, despite the patient continuing to show no symptoms, laboratory investigations identified mild thrombocytopenia (platelet count 134 $\times 10^{9}$ cells/L), elevated immunoglobulin $\mathrm{M}$ $(2.65 \mathrm{~g} / \mathrm{L})$, complementemia $(\mathrm{C} 30.76 \mathrm{~g} / \mathrm{L}, \mathrm{C} 4$ $<0.06 \mathrm{~g} / \mathrm{L}$ ), and the presence of antinuclear and anticardiolipin antibodies and rheumatoid factor (37 [normal 0-15] IU/mL). However, the results of tests for antibodies to cyclic citrullinated peptide (anti-CCP) and double-stranded DNA were negative.

\section{Discussion}

Parvovirus B19 is a single-stranded DNA virus. Transmission predominantly occurs via respiratory droplets and, to a lesser extent, vertically (i.e., mother to child). Transmission via blood products and percutaneous exposure to blood has been reported. ${ }^{1}$ Infection is most prevalent in school-aged children, with cases tending to peak 
during the late winter to early summer. During the highly contagious 5- to 10-day incubation phase of the virus, patients often show no symptoms or have mild fevers and influenza-like symptoms, followed by about 5 days of viremia correlating with the presentation of systemic clinical symptoms. ${ }^{2,3}$

\section{Clinical manifestations}

About one-quarter of parvovirus B19 infections are asymptomatic. ${ }^{1}$ For infections that do become symptomatic, manifestations can be subdivided into 5 clinical entities: erythema infectiosum or fifth disease, parvovirus arthritis, bone marrow failure, transient aplastic crisis and fetal infection. ${ }^{4}$ In children, the most common presentation is erythema infectiosum, a self-limiting syndrome ${ }^{1}$ characterized by a nonspecific viral prodrome, followed by a "slapped cheek" facial rash with circumoral pallor. Subsequent to this, an erythematous maculopapular exanthem develops over the limbs and trunk. ${ }^{4}$ In contrast to the malar rash associated with systemic lupus erythematosus, there is nasal sparing with erythema infectiosum. ${ }^{1}$

Parvovirus arthritis is the most common manifestation of the infection in adults, affecting $60 \%$ of women and $30 \%$ of men. ${ }^{1}$ Arthritis tends to persist for a few weeks and is typically symmetric and confined to the hands, knees, ankles, wrists and feet. ${ }^{5}$ Although persistent or recurrent arthritis in the absence of a rash can be confused with rheumatoid arthritis, parvovirus arthropathy does not cause joint destruction. ${ }^{6}$

Despite its seemingly benign course, parvovirus infection can be life-threatening to specific populations. Bone marrow suppression and red cell aplasia may develop in patients who are immunocompromised. A transient aplastic crisis may occur in patients with underlying hemoglobinopathies, hemolytic disorders and high red blood cell turnover. ${ }^{4}$

Fetal infection during pregnancy can be complicated by intrauterine fetal death and nonimmune hydrops fetalis. Although up to $50 \%$ of pregnant women with this infection will have no symptoms, maternal infection in the first trimester is associated with a $19 \%$ risk of fetal death. ${ }^{2}$ Thereafter, there is a $15 \%$ risk of fetal death during weeks $13-20$, and a $6 \%$ risk of fetal death after week $20 .{ }^{2,7}$ Up to $12.5 \%$ of fetuses with parvovirus infection will have hydrops fetalis, with the peak incidence occurring between 17 and 24 weeks' gestation. ${ }^{2}$

\section{Diagnosis and treatment}

Acute parvovirus infection is confirmed with serologic and PCR testing. Parvovirus B19 immunglobin $\mathrm{M}$ antibodies are detectable 7-
10 days after exposure and persist for about 15 months. ${ }^{8}$ Immunoglobulin $\mathrm{G}$ antibodies appear 15 days after exposure, persist for life and confer immunity. ${ }^{1}$ Infection in an immunocompetent host is confirmed by serologic testing for B19specific antibodies via enzyme immunoassay. ${ }^{1}$ Because the viremic period can last 1-2 weeks, PCR testing can be useful in making the diagnosis in pregnant women with a history of exposure, because maternal immunoglobulin $\mathrm{M}$ can be below detectable levels. ${ }^{9,10}$ The same is true for patients who are immunocompromised.

No specific antiviral treatment exists for parvoviral infections. ${ }^{5}$ Therapy is supportive, and rashes and arthralgias are self-limited and may be treated with anti-inflammatory drugs.

\section{Parvovirus mimicking systemic lupus erythematosus}

There are case reports of acute parvovirus infection causing a transient subclinical autoimmune state manifesting as the presence of autoantibodies. ${ }^{11}$ About $25 \%-68 \%$ of patients mount a transient autoantibody response after infection, ${ }^{12}$ including antinuclear antibodies, rheumatoid factor, and antibodies to double-stranded DNA, phospholipids, ribonucleoprotein, Sjögren syndrome antigens A and B and topoisomerase scl70. The proposed mechanisms include molecular mimicry and epitope spreading, as well as abnor-

\begin{tabular}{|lll|}
\hline $\begin{array}{l}\text { Box 1: Clinical features that may help to distinguish parvovirus B19 } \\
\text { infection from systemic lupus erythematosus }\end{array}$ \\
\hline Clinical feature & $\begin{array}{l}\text { Parvovirus B19 } \\
\text { infection }\end{array}$ & \multicolumn{1}{c|}{ Lupus } \\
\hline Course & Self-limiting & Persistent \\
\hline Severity & Mild & Mild to severe \\
\hline Persistent fevers & Rare & May be present \\
\hline Anemia & Secondary to & $\begin{array}{l}\text { Secondary to } \\
\text { autoimmune } \\
\text { hemolysis }\end{array}$ \\
\hline Reticulocyte count & suppression & $\begin{array}{l}\text { Normal to high } \\
\text { in presence of } \\
\text { evidence of } \\
\text { hemolysis }\end{array}$ \\
\hline $\begin{array}{l}\text { Splenomegaly } \\
\text { pow in } \\
\text { bresence of }\end{array}$ & suppression & May be present \\
\hline Discoid lesions, alopecia & Rare & May be present \\
\hline Oral ulcers & Absent & May be present \\
\hline Raynaud phenomenon & Rare & May be present \\
\hline $\begin{array}{l}\text { Neurologic (seizures, psychosis, } \\
\text { chorea) and ocular symptoms }\end{array}$ & Absent & May be present \\
\hline $\begin{array}{l}\text { Gastrointestinal involvement } \\
\text { obstruction/pseudo-obstruction) }\end{array}$ & Rare & May be present \\
\hline Cardiac involvement & Rare & May be present \\
\hline Renal involvement & Ray be present \\
\hline
\end{tabular}


mal apoptosis of bone marrow erythroid precursors infected with the virus. ${ }^{13}$ The associated autoantibodies and abnormal test results seen with parvovirus infection generally resolve within 3 months $;{ }^{14}$ however, chronic persistence of these autoantibodies after infection has rarely been described in the literature.

Our patient's clinical symptoms, exposure history, positive serologic test results for immunoglobulin M and PCR test results showing parvovirus B19 supported the diagnosis of an acute parvovirus infection. However, the possibility of a first presentation of a concomitant rheumatological condition such as systemic lupus erythematosus could not be excluded because of the other positive serologic test results and evidence of hypocomplementemia. In the appropriate clinical setting, despite its poor specificity, the presence of antinuclear antibody is $93 \%$ sensitive for systemic lupus erythematosus; the presence of antibodies to double-stranded DNA is 70\% sensitive and $95 \%$ specific. $^{15}$

Although they are predominantly used for research purposes, our patient met 4 of the 11 American College of Rheumatology criteria for a clinical diagnosis of systemic lupus erythematosus, with arthropathy, leukopenia and the presence of two types of antibody. ${ }^{16}$ These criteria are associated with a sensitivity of $85 \%$ and a specificity of $95 \%$ for systemic lupus erythematosus. ${ }^{16,17}$

In the absence of a sound epidemiologic and exposure history, clinicians may be misled toward diagnosing a connective tissue disorder. Furthermore, in the context of the new criteria for diagnosing rheumatoid arthritis that emphasize early detection and treatment ${ }^{18}$ given the nonspecific autoantibody response that accompanies parvoviral arthritis, patients may score sufficiently to warrant the use of immunosuppressive therapy. ${ }^{18}$ This highlights the importance of an accurate epidemiologic history to establish the diagnosis.

Distinguishing between a recent parvovirus B19 infection and a first presentation of systemic lupus erythematosus can be challenging in the acute setting. Clinical clues can help to differentiate the 2 entities (Box 1). ${ }^{19}$ To avoid an incorrect or premature diagnosis of lupus, health care providers should be aware of the association between autoantibodies and parvovirus infection. This is especially relevant in patients who present with persistent joint symptoms after their rash has resolved. Although high-level evidence is lacking, in the acute setting (i.e., $<6$ wk of symptoms), clinicians may want to consider confirmatory testing for acute parvovirus infection in patients with a compatible history and clinical picture when the diagnosis is unclear.

Despite confirmation of an acute parvovirus infection in our patient, one might wonder whether the persistence of autoimmune markers may eventually lead to the diagnosis of a connective tissue disease. It is also possible that the conditions are unrelated and that the patient had a pre-existing asymptomatic connective tissue disorder with elevated autoantibodies before the viral infection. Therein lies the challenge facing clinicians, as only time will tell.

\section{References}

1. Heegaard ED, Brown KE. Human parvovirus B19. Clin Microbiol Rev 2002;15:485-505.

2. Lamont RF, Sobel JD, Vaisbuch E, et al. Parvovirus B19 infection in human pregnancy. BJOG 2011;118:175-86.

3. Anderson MJ, Higgins PG, Davis LR, et al. Experimental parvoviral infection in humans. J Infect Dis 1985;152:257-65.

4. Brown KE, Young NS. Parvovirus B19 in human disease. Annu Rev Med 1997;48:59-67.

5. Young NS, Brown KE. Parvovirus B19. N Engl J Med 2004;350: 586-97.

6. Speyer I, Breedveld FC, Dijkmans BA. Human parvovirus B19 infection is not followed by inflammatory joint disease during long term follow-up. A retrospective study of 54 patients. Clin Exp Rheumatol 1998;16:576-8.

7. Risks associated with human parvovirus B19 infection. $M M W R$ Morb Mortal Wkly Rep 1989;38:81-8.

8. Erdman DD, Usher MJ, Tsou C, et al. Human parvovirus B19 specific $\operatorname{IgG}, \operatorname{IgA}$, and $\operatorname{IgM}$ antibodies and DNA in serum specimens from persons with erythema infectiosum. J Med Virol 1991;35:110-5.

9. Enders M, Weidner A, Rosenthal T, et al. Improved diagnosis of gestational parvovirus B19 infection at the time of nonimmune fetal hydrops. J Infect Dis 2008;197:58-62.

10. Broliden K, Tolfyenstam T, Norbeck O. Clinical aspects of parvovirus B19 infection. J Intern Med 2006;260:285-304.

11. Soloninka CA, Anderson MJ, Laskin CA. AntiDNA and antilymphocyte antibodies during acute infection with human parvovirus B19. J Rheumatol 1989;16:777-81.

12. Meyer O. Parvovirus B19 and autoimmune diseases. Joint Bone Spine 2003;70:6-11.

13. Moore TL. Parvovirus-associated arthritis. Curr Opin Rheumatol 2000;12:289-94.

14. Sève $\mathrm{P}$, Ferry $\mathrm{T}$, Koenig $\mathrm{M}$, et al. Lupus-like presentation of parvovirus B19 infection. Semin Arthritis Rheum 2005;34:642-8.

15. Solomon DH, Kavanaugh AJ, Schur PH, et al. Evidence-based guidelines for the use of immunologic tests: antinuclear antibody testing. Arthritis Rheum 2002;47:434-44.

16. Tan EM, Cohen AS, Fries JF, et al. The 1982 revised criteria for the classification of systemic lupus erythematosus. Arthritis Rheum 1982; 25:1271-77.

17. Hochberg MC. Updating the American College of Rheumatology revised criteria for the classification of systemic lupus erythematosus. Arthritis Rheum 1997;40:1725.

18. Aletaha D, Neogi T, Silman AJ, et al. 2010 Rheumatoid arthritis classification criteria. Arthritis Rheum 2010;62:2569-81.

19. Severin MC, Levy Y, Shoenfeld Y. Systemic lupus erythematosus and parvovirus B19: Casual coincidence or causative culprit? Clin Rev Allergy Immunol 2003;25:41-8.

Affiliations: Department of Medicine, McMaster University, Hamilton, Ont.

Contributors: Mohan Cooray, Douglas Wright and Ameen Patel assessed the patient's case and contributed to its analysis. Joshua Manolakos contributed to the analysis of the case. Shariq Haider contributed to the interpretation of the case. All of the authors helped draft the manuscript, revised it critically for important intellectual content and approved the final version submitted for publication. 